\title{
EL SAGRARIO DE LA CATEDRAL DE ÁVILA: UN TABERNACOLO ITALIANO EN ESPAÑA
}

\section{THE TABERNACLE OF THE CATHEDRAL OF ÁVILA: AN ITALIAN TABERNACOLO IN SPAIN}

\author{
Ismael Mont MuÑoz \\ Universidad de Salamanca. España \\ ismaelmontmuñoz@usal.es
}

Vasco de la Zarza ha pasado a la Historia del Arte como uno de los introductores de la escultura del Renacimiento italiano en España. Actualmente, solo conocemos trabajos suyos dentro de las fronteras españolas, pero la estrecha vinculación que presentan con el arte italiano ha permitido plantear la hipótesis de que estuvo en Italia. Una de sus obras cumbres es el sagrario del retablo mayor de la catedral de Ávila. La excepcionalidad de esta pieza se debe a su valor artístico, histórico, iconográfico y simbólico. Pero además de todo ello, destaca porque sigue un modelo de sagrario único en la España de su época, que nos remite directamente a piezas italianas, tema que no ha sido tratado con anterioridad.

Palabras clave: sagrario; retablo; italiano; modelo; Renacimiento.

Vasco de la Zarza has gone down in History of Art as one of the initiators of Italian Renaissance sculpture in Spain. All the works we know are within the Spanish borders, but the close relation they have with Italian art has allowed us to hypothesize he was in Italy. One of his masterpieces is the tabernacle of the main altarpiece of the Cathedral of Ávila. The exceptionality of this piece of art is due to its artistic, historical, iconographic and symbolic value. In addition, it stands out because it follows a model of a unique tabernacle in the Spain of its time, which refers us directly to Italian pieces, a subject that hasn't been treated before.

Keywords: tabernacle; altarpiece; Italian; model; Renaissance.

\section{INTRODUCCIÓN}

La visita a la catedral de Ávila exige una parada obligada frente a su retablo mayor (Figura 1), que se erige como uno de los símbolos de la transición del Gótico al Renacimiento en Castilla. Esta obra se inició en 1499 y en ella participó uno de los principales representantes de la pintura española de esta época: Pedro 
Berruguete, quien realizó algunas tablas, tras su vuelta de la corte de Federico da Montefeltro en Urbino ${ }^{1}$. El retablo fue rematado hacia 1510 con el montaje del marco por Vasco de la Zarza (Figura 2). En él introdujo un amplio repertorio decorativo de sirenas, ninfas o sátiros. El temprano empleo de estos elementos, como reflejan muchas de sus creaciones artísticas, se ha convertido en uno de los principales argumentos a favor de la posibilidad de que este artista estuviera en Italia, a pesar de que todavía no se ha podido aportar ninguna prueba documental que permita confirmarlo ${ }^{2}$. Este marco fue uno de los primeros encargos conocidos de este artista en Ávila. Tras su realización, solo faltaba por completar un espacio vacío que se había reservado en el centro de la predela del retablo, destinado a acoger el sagrario (Figura 3). Por lo tanto, el estudio de esta pieza debe partir de la premisa de que se encuentra asociada estructural e iconográficamente al retablo mayor, a pesar de su carácter autónomo.

El sagrario nos sorprende a primer golpe de vista por su calidad escultórica, imponencia y particularidad estructural. Esta última característica se debe a que esta obra constituye en sí misma un pequeño retablo realizado en alabastro, caso único si hablamos de los sagrarios españoles de esta época que conocemos. En el ámbito español, las medidas de esta obra resultan excepcionalmente grandes para un sagrario (1,75 m de ancho x 2,20 m de alto), a cuya altura hay que añadir el grupo escultórico de la Piedad (de unos $25 \mathrm{~cm}$ ). Su estructura se organiza en dos cuerpos divididos en tres calles principales y dos más estrechas, apoyado todo ello sobre una predela. El conjunto se remata con una crestería, sobre la que se alza la Piedad (Figura 4). De este modo, se trata de un microrretablo dentro del retablo mayor. Se podría considerar que funciona como un retablo porque acoge un programa iconográfico completo y de una complejidad extraordinaria.

Sobre esta obra se representan siete escenas de la Pasión en torno a la puerta que custodia el Santísimo Sacramento, modificada en el siglo XVIII. En el centro de la predela se dispone una pareja de ángeles arrodillados adorando un cáliz eucarístico ricamente decorado, que viene a constituir la base del cuerpo central

${ }^{1}$ PARRADO DEL OLMO, José María: "Una nueva época: la Edad Moderna en la catedral de Ávila", en La catedral de Ávila. Nueve siglos de Historia y Arte. Zamudio, 2014, p. 257.

${ }^{2}$ Esta cuestión ya fue propuesta en 1901 por Manuel Gómez-Moreno, cuyo trabajo fue publicado por vez primera en GÓMEZ-MORENO MARTÍNEZ, Manuel: Catálogo Monumental de la provincia de Ávila. Ávila, 1983, pp. 101-102. Este tema también fue tratado en RUIZ-AYÚCAR Y ZURDO, María Jesús: La primera generación de escultores del s. XVI en Ávila. Vasco de la Zarza y su escuela. Vol. I. Ávila, 2009, pp. 105-109. El último estudio que se ha referido a este problema ha sido PEREDA ESPESO, Felipe: La arquitectura elocuente: el edificio de la Universidad de Salamanca bajo el reinado de Carlos $V$. Madrid, 2000, pp. 206-207. En este último trabajo se hace referencia a la citada obra de Manuel Gómez-Moreno y a otras dos del mismo autor que también proponen la estancia en Italia de Zarza. 
(Figura 5). El conjunto se completa con los escudos de la catedral, del obispo y del Cordero Místico, así como con un rico repertorio decorativo en el que encontramos las arma Christi, pelícanos y espigas, haciendo una clara alusión al carácter sacrificial de la Eucaristía.

\section{UN SAGRARIO ITALIANO}

La singularidad del modelo de esta obra y la ausencia de antecedentes y consecuentes directos en la escultura hispana no han sido explicados hasta la actualidad. Por este motivo, centraremos nuestro trabajo en tratar de aclarar este tema.

En 1518 se llamó a Vasco de la Zarza para que se encargase de esculpir el sagrario de la Iglesia Madre de Ávila. En el documento que recoge la orden para que se llevase al artista a la catedral se indica que la obra que haga "sea muy rica e tal que sea la mejor que pueda fazer". El microrretablo que esculpió el artista debió cumplir con creces las expectativas del cabildo catedralicio, pues realmente es de una calidad excepcional. Así, el resultado fue la creación de un trabajo con una perfección y coherencia conceptual y estructural extraordinarias, que están a la altura de una narración teológica excelentemente elaborada. Esto nos hace pensar que seguramente no se trate de un modelo desarrollado por vez primera. Sin embargo, en España no sabemos de la existencia de otros sagrarios que sigan un modelo parecido al de Ávila, ni que tengan tal empaque -y aún menos realizados en un material noble como el alabastro-. A pesar de ello, no podemos afirmar con seguridad que no hayan existido otras obras similares en el arte español, pues, como sabemos, lo que hoy conocemos no es todo lo que hubo.

Esta situación plantea la necesidad de buscar fuera de España otras creaciones que puedan estar relacionadas con la nuestra. Dicho rastreo nos conduce hasta Italia. Así, por diferentes partes de la geografía de este país -especialmente en Toscana y en Sicilia- conseguimos localizar numerosos sagrarios renacentistas que presentan muchos puntos en común con el modelo y la estructura del tabernáculo de Ávila.

A pesar de las particularidades de cada una de estas obras -llamadas tabernacoli en italiano-, siempre se trata de sagrarios realizados en mármol blanco, concebidos a modo de retablo y con una estructura simétrica dividida en partes regulares que acogen escenas diversas o repertorios decorativos. En algunos casos alcanzan grandes dimensiones, igual que sucede en el caso de Ávila. Son muchos los trabajos de referencia que se han dedicado al estudio de estas obras en Italia y los hemos tenido muy en cuenta, aunque no es nuestro objeto realizar un repaso de todos ellos.

${ }^{3}$ ACA (Archivo de la catedral de Ávila), Actas n ${ }^{\circ} 2,1518$, f. 59v. Recogido en RUIZAYÚCAR Y ZURDO, María Jesús: La primera generación..., op. cit., p. 260. 
La lista de ejemplos italianos que podríamos relacionar con el sagrario abulense es muy extensa, de modo que vamos a citar solo algunos de ellos. Dos modelos muy próximos al que estudiamos son el tabernacolo de Andrea di Piero Ferrucci, de hacia 1493, hoy en el Victoria \& Albert Museum, y el realizado por Andrea Sansovino en la Chiesa del Santo Spirito de Florencia, hacia 1490, que ya fue puesto en relación con la pieza española que estamos estudiando ${ }^{4}$. En ambos casos, observamos que en los cuerpos superiores de las calles laterales aparecen medallones que acogen diferentes figuras, como en el sagrario de Ávila. Fuera de Italia, pero realizado por un italiano, también podemos citar, por ejemplo, el tabernacolo esculpido por Gianmaria Mosca para la catedral de Cracovia en la década de $1530^{5}$. Esta obra, junto con la de Ávila, demuestran que este modelo de sagrario ejerció su influencia más allá de las fronteras italianas. Otro ejemplo que sigue una estructura parecida es el esculpido entre 1481 y 1483 por Mino da Fiesole, para la Cappella del Miracolo de la iglesia de Sant'Ambrogio de Florencia. En otros casos se simplifican mucho y son concebidos a modo de "pequeños retablos" o "cuadros", como el del Museo Diocesano de Oppido Palmi (Calabria), obra de un taller de Messina del siglo XVI; el de Santa Maria in Trastevere, en Roma, realizado por Mino da Fiesole en el siglo XV; el de Domenico Rosselli, en Scarperia (provincia de Florencia), del siglo XV; también en Colle di Val d'Elsa (provincia de Siena) se conserva otro sagrario similar atribuido al mismo artista.

Sin embargo, en Sicilia vamos a encontrar una gran cantidad de sagrarios que están relacionados de un modo mucho más directo con la pieza abulense que nos ocupa. Entre los numerosos ejemplos que podemos señalar, encontramos el de la iglesia de Santa Zita de Palermo; los de las iglesias parroquiales de Tusa, Ciminna o Ficarra; el de la catedral de Mazara del Vallo; el del Museo Regionale Agostino Pepoli, en Trapani (Figura 6); o el de la Badia Grande de Alcamo. Algunas de estas creaciones han sido atribuidas a Antonello Gagini y su taller, activo en Sicilia durante la primera mitad del siglo $\mathrm{XVI}^{6}$. Estas obras constituyen la continuación de un tipo de sagrario desarrollado en diferentes lugares de Sicilia desde los últimos años del siglo XV. Entre ellos, podemos destacar los sagrarios de las iglesias de Isnello, Pollina o Collesano ${ }^{7}$ (Figura 7). Estos tabernáculos ya fueron puestos en relación con sus homólogos toscanos ${ }^{8}$, a los que ya nos hemos referido.

${ }^{4}$ Ibidem, p. 261.

${ }^{5}$ MIZIOLEK, Jerzy: "Opus egregium ac spectandum. Il tabernacolo eucaristico di Gianmaria Mosca, detto il Padovano, per la cattedrale di Cracovia”, Mitteilungen des Kunsthistorischen Institutes in Florenz, 37, 1993, pp. 303-336.

${ }^{6}$ KRUFT, Hanno-Walter: Antonello Gagini und seine söhne. Munich, 1980.

7 Estas obras fueron objeto del estudio de KRUFT, Hanno-Walter: Domenico Gagini und seine werkstatt. Munich, 1972.

${ }^{8}$ FAILLA, Marco: "La commitenza del vescovo Francesco Vitale (1484-1492) tra Collesano, Isnello e Cefalù e la diffusione dei tabernacoli marmorei di tipología rinascimentale 
Todas estas obras sicilianas reproducen el mismo modelo de sagrario desarrollado en Ávila en fechas muy próximas a la creación de esta obra. No obstante, en el caso español se incorporan, como novedad, dos calles más estrechas entre las tres principales. Además de seguir la misma estructura de sagrario, las obras sicilianas que hemos citado coinciden con la de Ávila en el protagonismo que otorgan a la representación de la adoración del Santísimo Sacramento por figuras angelicales. A través de ello se pretende enfatizar la presencia de Cristo en la Eucaristía, cuestión ampliamente debatida por la teología medieval. La importancia concedida a estos ángeles adoradores hace que el sagrario de Ávila, los sagrarios sicilianos y muchos de los que encontramos en otras partes de Italia constituyan auténticos "retablos eucarísticos", que se convierten en monumentos dedicados a la exaltación del Santísimo Sacramento. Esto se explica porque estas obras fueron creadas en un momento histórico en el que la devoción y el culto a la Eucaristía experimentaron unas cotas jamás alcanzadas en la Iglesia Católica hasta ese momento.

Al igual que en el caso abulense, algunos de estos retablos sicilianos además presentan dos grandes medallones en los cuerpos superiores de las calles laterales, como el del Museo Regionale Agostino Pepoli de Trapani, el de la iglesia de Ciminna o el de Badia Grande, en Alcamo (Figura 8). Este último muestra la misma estructura narrativa planteada en Ávila, con todo un conjunto de escenas del ciclo de la Pasión rodeando la puerta del sagrario. Así, en esta obra, como en las citadas de Ficarra, Tusa o Ciminna, se destaca de un modo especial el concepto de Eucaristía como Memoria Passionis y el carácter sacrificial de la celebración eucarística. Estas mismas ideas son las que rigen el programa iconográfico y las representaciones simbólicas del sagrario abulense.

Todas ellas son obras del Quattrocento y del Cinquecento italiano y, por tanto, realizadas antes, durante y después del sagrario de la catedral de Ávila. De este modo, la obra objeto de nuestro estudio se inserta dentro de una tradición escultórica italiana que consolidó un modelo renacentista de tabernacoli, que no encuentra otros ecos en la España de la primera etapa del Renacimiento. Según parece, la obra que nos ocupa, más que copiar un sagrario concreto, sigue una idea de sagrario, adaptándolo a las necesidades estructurales, espaciales e iconográficas del caso abulense. Así, no podemos decir que reproduce una determinada obra, sino un determinado modelo.

nel territorio delle Madonie", en Arte e storia delle Madonie. Studi per Nico Marino. T. III. Cefalù, 2016, p. 110. 


\section{AHORA BIEN, ¿POR QUÉ SE REALIZA EN ÁVILA ESTE RETABLO EUCARÍSTICO SIGUIENDO EL EMPAQUE Y EL MODELO DE LOS SAGRARIOS RENACENTISTAS DE ITALIA?}

Probablemente encontremos la respuesta dos décadas antes de la realización de esta obra. Necesitamos retroceder hasta 1499, una fecha que hemos recordado anteriormente porque fue el año en el que se inició el retablo mayor de la Iglesia Madre de Ávila. Como ya hemos aclarado anteriormente, fue concebido con un espacio vacío en el centro de la predela que iría destinado al sagrario. Por aquellas fechas, ocupaba la cátedra abulense el obispo Alonso Carrillo de Albornoz, llegado a Ávila en 1496 tras ser obispo de Catania desde 1486.

Aunque este obispo murió en 1514 -cuatro años antes del inicio del sagrario-, asistió a la renovación del retablo mayor de principio a fin. Ya hemos destacado previamente que el sagrario, a pesar de ser una obra autónoma, forma parte del retablo y lo completa. Por ello, no resultaría extraño pensar que Alonso Carrillo tuviera en mente una idea para el sagrario, y que esta se llevara a la práctica tras su muerte.

Para defender esta hipótesis nos apoyamos en la estancia de este obispo en Catania durante varios años, lo que le permitió conocer de primera mano el arte sacro italiano. Pero también le hizo adquirir un gusto artístico que le condujo a impulsar en España toda una serie de obras directamente relacionadas con el Renacimiento italiano -dentro y fuera de la catedral de Ávila-. Durante su episcopado abulense promovió numerosas intervenciones artísticas en la catedral, como el sepulcro de El Tostado, que se caracterizan por su estrecha relación con el arte del Renacimiento en Italia. Debido al desarrollo de todas estas obras, Alonso Carrillo ha pasado a la Historia como introductor del arte del Renacimiento en la catedral de Ávila, abriendo una de las etapas de mayor esplendor artístico de este templo. Así, se convirtió en un importante "mecenas italiano en España", que hasta ahora no ha recibido la atención suficiente por la historiografía. Por este motivo, y porque no hubo en estas fechas ningún eclesiástico en la catedral tan vinculado a Italia y al arte de este país como Carrillo, es bastante probable que este obispo pudiera haber realizado la propuesta para el sagrario de Ávila. Esta, estaría inspirada directamente en los tabernacoli que en aquella época se estaban realizando en Italia y que nuestro obispo, seguramente, pudo conocer. No olvidemos los particulares paralelismos existentes entre la obra que nos ocupa y muchos sagrarios de Sicilia, donde Alonso Carrillo ejerció como prelado justo antes de llegar a Ávila.

Este hecho resulta especialmente significativo, pues los ya mencionados sagrarios sicilianos de Isnello, Pollina y Collesano -cercanos a Cefalù-, han sido fechados en los mismos años en los que Carrillo ocupó la sede episcopal de la catedral de Catania. Además, han sido considerados como fruto del mecenazgo de Francesco Vitale, obispo de Cefalù entre 1486 y 1492. Este personaje fue preceptor y 
secretario de Fernando el Católico, por lo que se trata de un hombre muy cercano a los Reyes Católicos ${ }^{9}$. Lo mismo sucede con Alonso Carrillo, que colaboró estrechamente con estos monarcas en el proceso de reforma de la Iglesia Católica en España. De este modo, no solo coincidió en tiempo y espacio con la realización de los citados sagrarios sicilianos, sino también con su promotor, con el que además compartía formar parte del círculo de personas más próximo de los reyes de Castilla y Aragón ${ }^{10}$. De este modo, se reúnen toda una serie de factores que pudieron favorecer el contacto entre ambas figuras históricas, con todo lo que esto podría implicar a nivel artístico.

Otra posibilidad que no debemos descartar es que el propio autor material de la obra, Vasco de la Zarza, pudiera haber sugerido este modelo de sagrario. Como ya hemos indicado, el concepto y el estilo de los trabajos de este artista han dado lugar a plantear que este escultor viajó a Italia, dando claras muestras de esta hipotética experiencia artística a su vuelta a España. Es bastante posible, que de haberse realizado este viaje, hubiera tenido Sicilia como destino. Uno de los argumentos que se han aportado para defender esta hipótesis es la estrecha relación que Vasco de la Zarza mantuvo con la noble abulense María Dávila, esposa de Fernando de Acuña, quien fue virrey de Sicilia de 1489 a 1494. Además de los vínculos personales entre estos personajes, tras la vuelta desde Palermo a España de la virreina, esta realizó varios encargos artísticos a Zarza en Ávila ${ }^{11}$. Asimismo, se ha propuesto que Zarza pudo trabajar, o conocer muy de cerca, el taller de la familia Gagini ${ }^{12}$, asentada en Sicilia desde la segunda mitad del siglo XV. No olvidemos que algunos de los sagrarios que hemos relacionado con el de Ávila han sido atribuidos a esta saga de artistas y sus talleres. Debido a todo ello, nos encontramos de nuevo ante un personaje que pudo estar vinculado a esta isla y a su ambiente artístico, al igual que el obispo Alonso Carrillo.

De este modo, la estrecha relación que presenta el sagrario abulense con sus homólogos sicilianos, nos hace pensar que la idea de la pieza que nos ocupa surge de una persona o personas que conocieron de manera directa estas obras. Así pues, no se trata de una simple imitación, sino que pone de manifiesto una perfecta comprensión del concepto de estos sagrarios.

${ }^{9}$ Ibidem, pp. 106-112.

${ }^{10}$ RÍOS RODRÍGUEZ, María Luz: "La preparación de la reforma en Galicia. Alonso Carrillo de Albornoz y la diócesis auriense en 1489”, Espacio, Tiempo y Forma (Serie III, Historia Medieval), 13, 2000, pp. 325-339.

${ }^{11}$ RUIZ-AYÚCAR Y ZURDO, María Jesús: La primera generación..., op. cit.

12 PEREDA ESPESO, Felipe: La arquitectura elocuente..., op. cit., p. 206. 


\section{CONCLUSIÓN}

El estudio del sagrario de Ávila en relación a los tabernacoli italianos permite ampliar el catálogo de obras italianas que influyeron en la expansión del Renacimiento italiano en España y abre una nueva e interesante línea de investigación no abordada hasta ahora.

Todo ello nos hace reflexionar sobre el estudio de las relaciones entre el Renacimiento italiano y el arte español. Aunque este tema ha sido objeto de numerosos estudios de gran valor desde hace mucho tiempo, aún quedan muchas cuestiones que necesitan ser abordadas, como pone de manifiesto, por ejemplo, nuestro $s a$ grario italiano.

Fecha de recepción: 6 de septiembre de 2018

Fecha de aceptación: 5 de febrero de 2019 


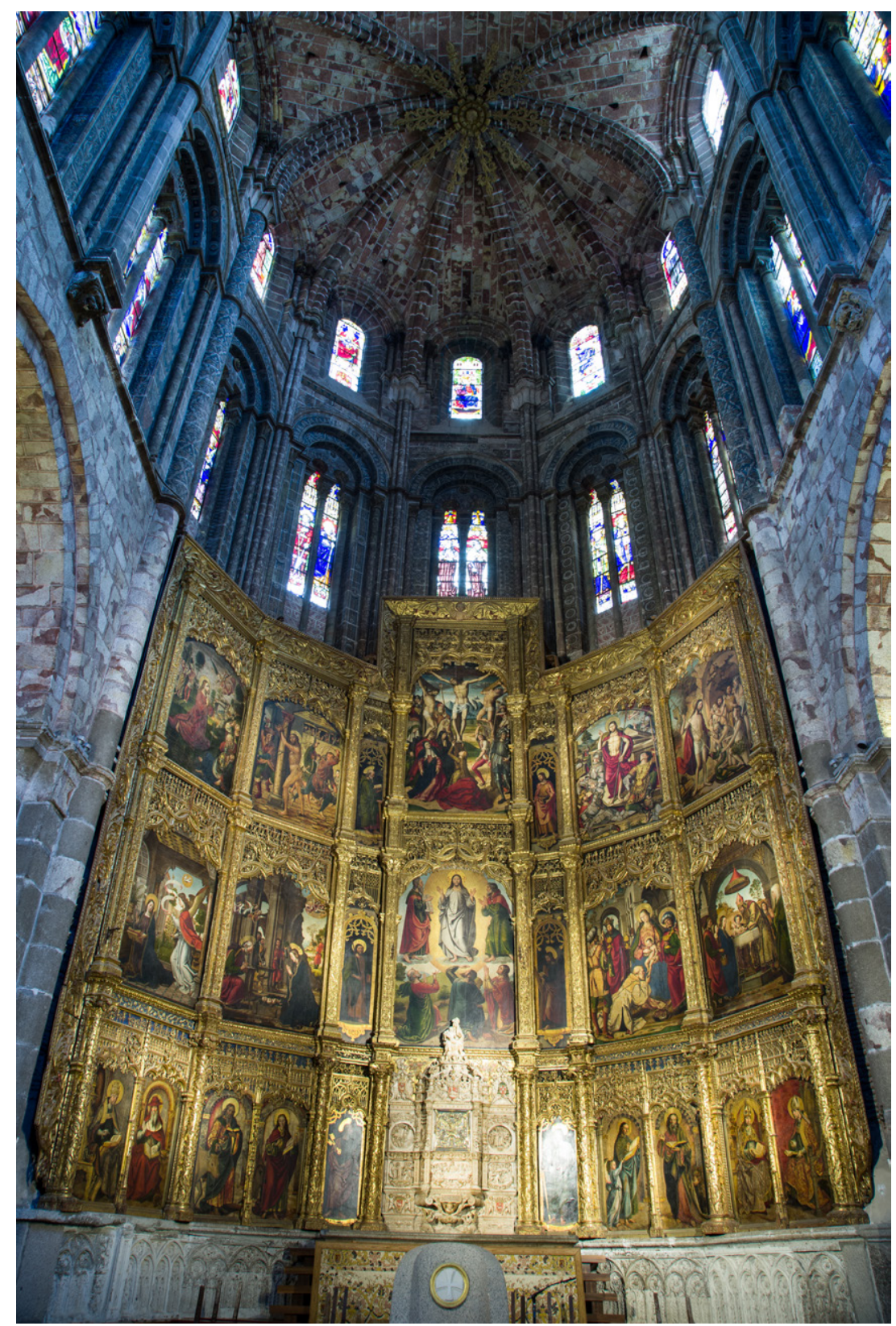

Figura 1. Varios autores, Retablo mayor, 1499-1522, catedral de Ávila. Foto: Isabel García Muñoz. 


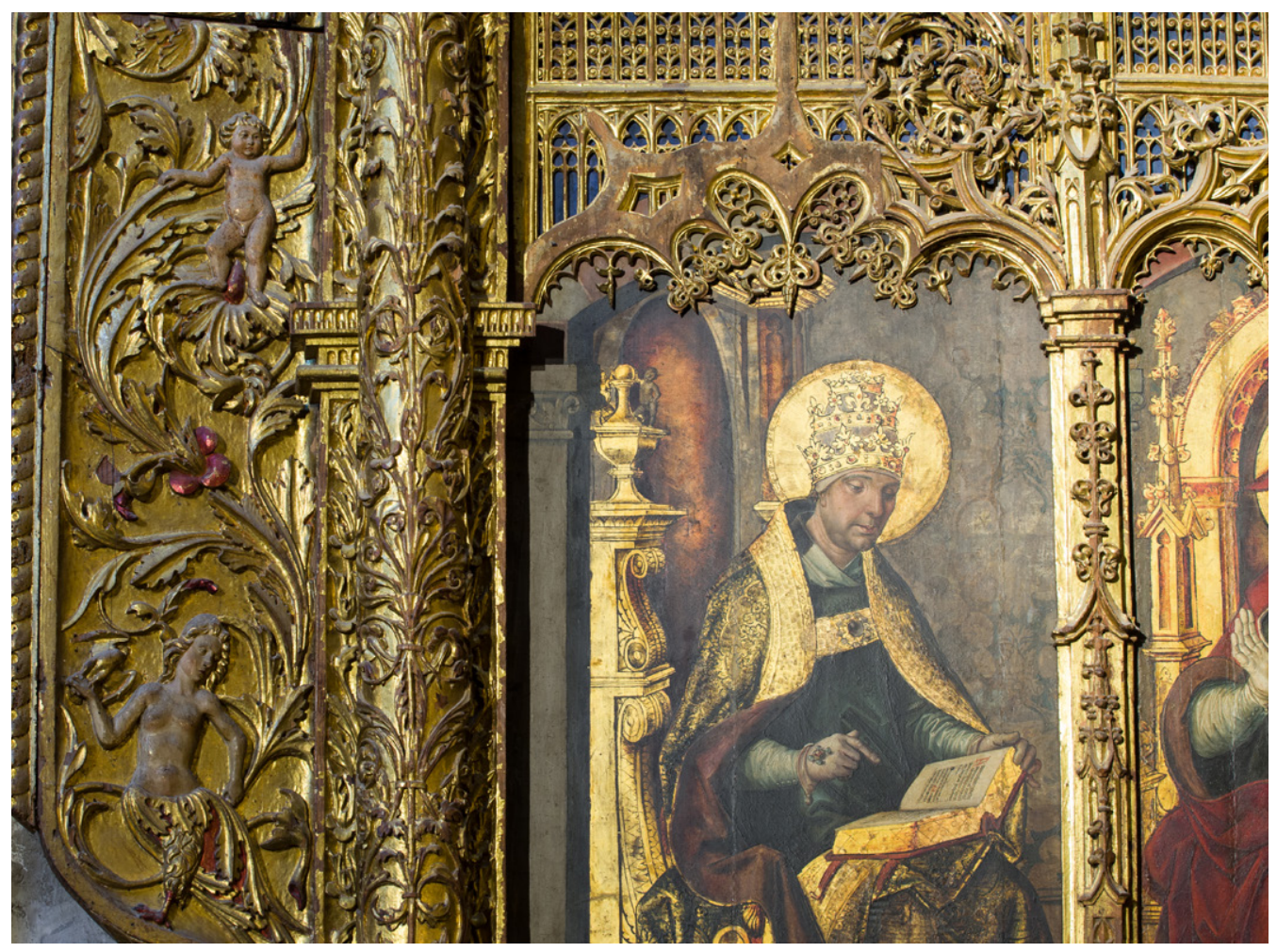

Figura 2. Vasco de la Zarza, Marco del retablo mayor (detalle), hacia 1510, catedral de Ávila. Foto: Isabel García Muñoz. 


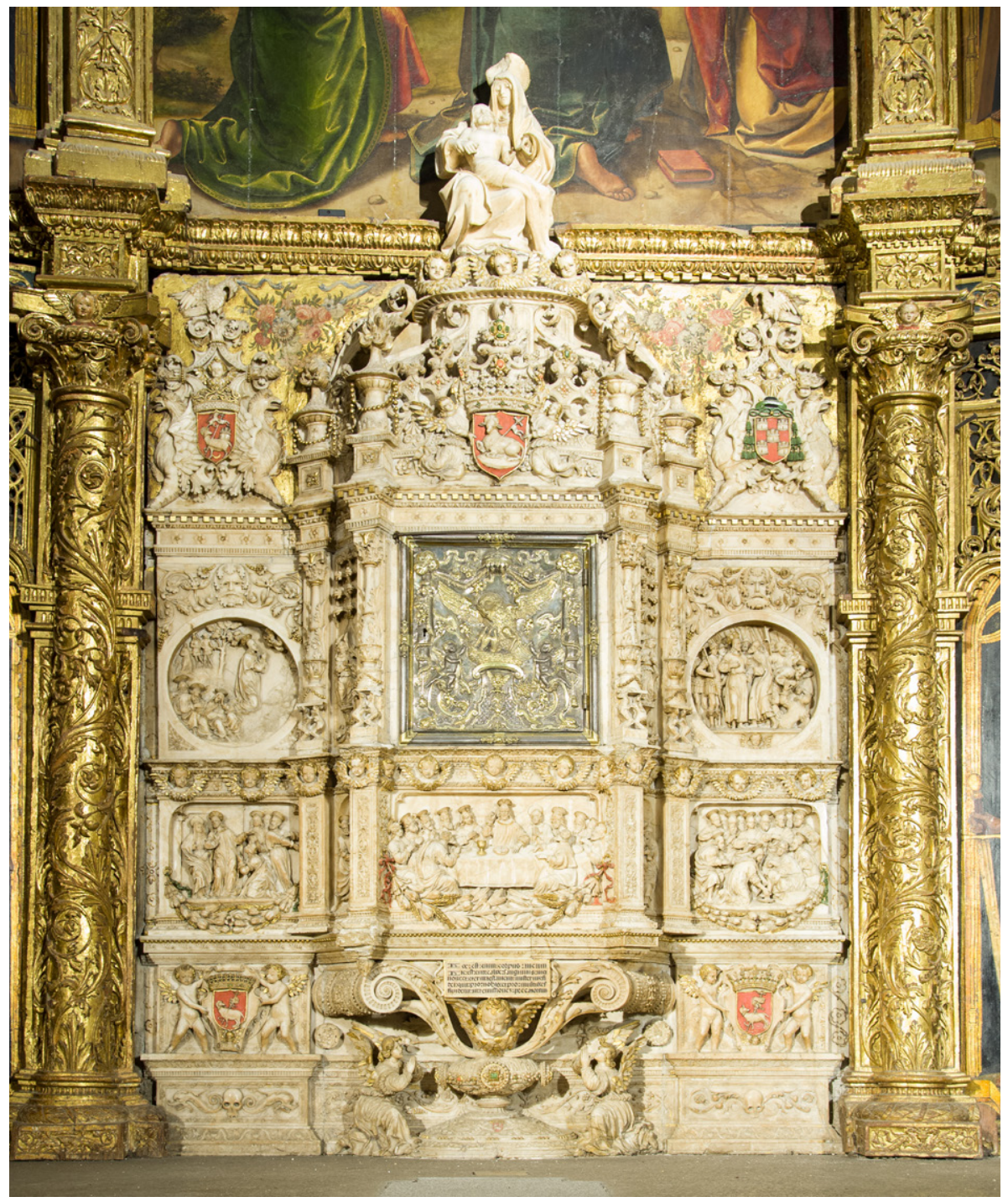

Figura 3. Vasco de la Zarza, Sagrario del retablo mayor, 1518/1519-1522, catedral de Ávila. Foto: Isabel García Muñoz. 


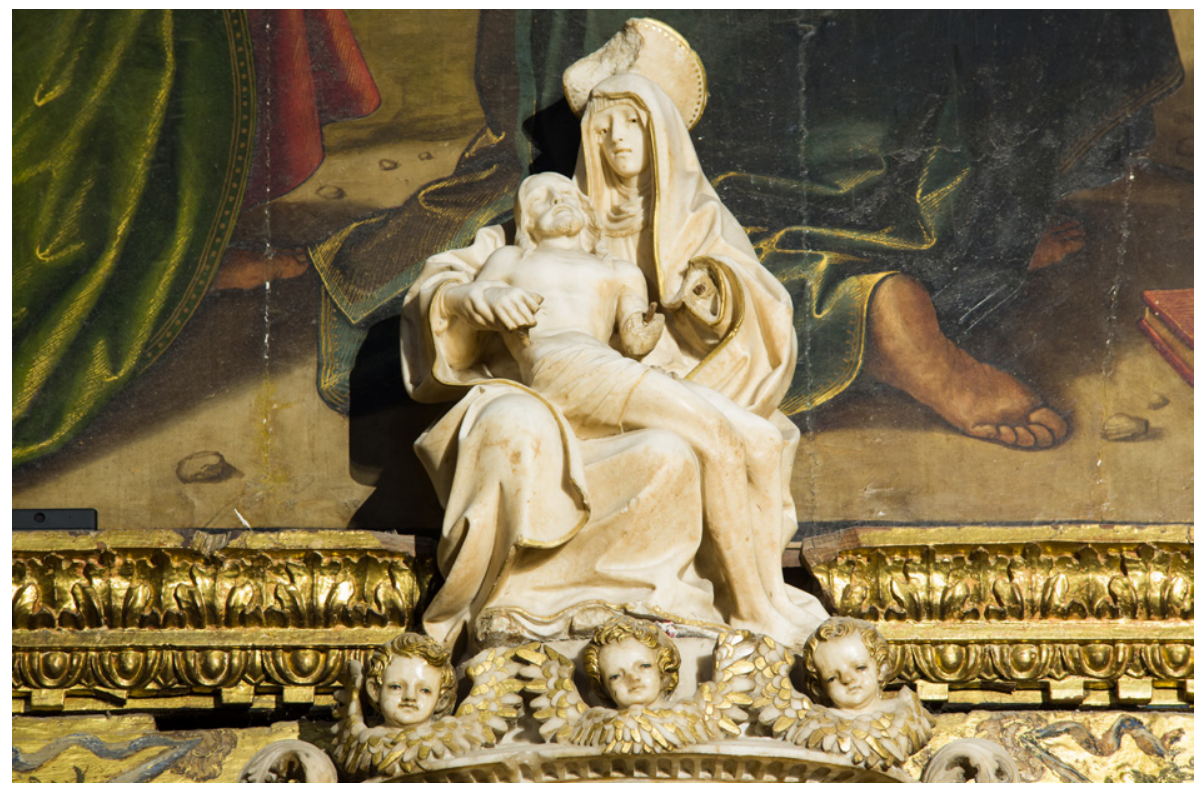

Figura 4. Vasco de la Zarza, Piedad del sagrario (detalle), 1518/1519-1522, catedral de Ávila. Foto: Isabel García Muñoz.

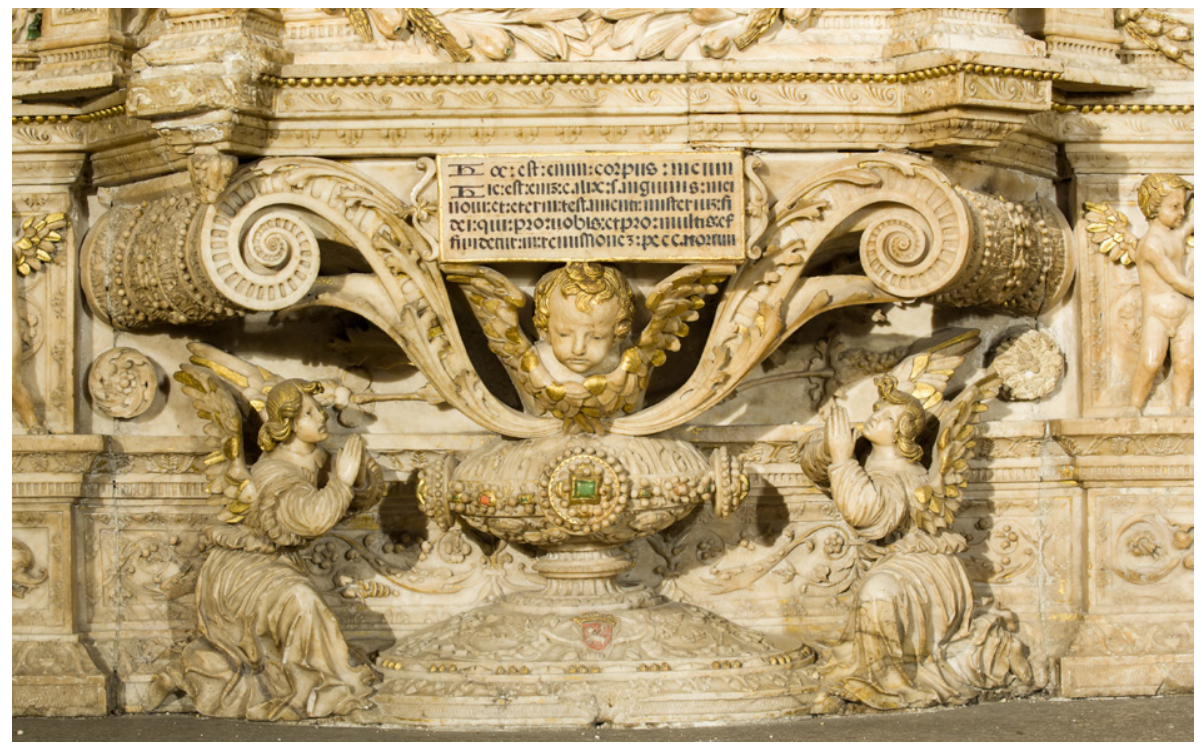

Figura 5. Vasco de la Zarza, Pareja de ángeles adorando el cáliz del sagrario (detalle), 1518/1519-1522, catedral de Ávila. Foto: Isabel García Muñoz. 
Figura 6. Atribuido a Antone1lo Gagini, Sagrario, principios del siglo XVI, Museo Regionale Agostino Pepoli (Trapani, Sicilia). Fotografía reproducida en KRUFT, Hanno-Walter: Antonello Gagini und seine söhne. Munich, 1980.

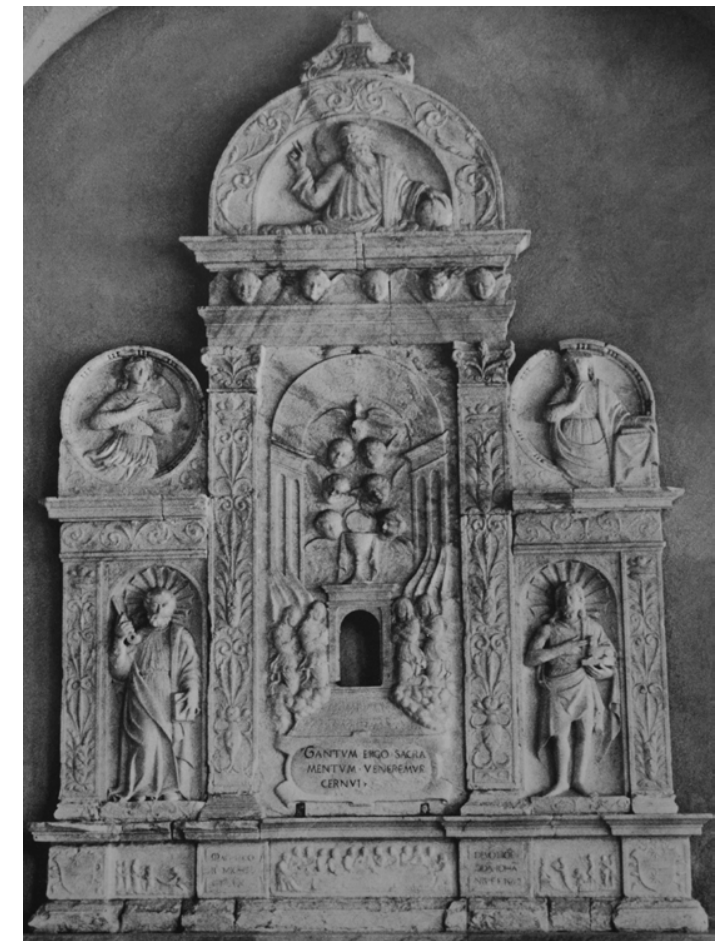

Figura 7. Taller siciliano, Sagrario, fines del siglo XV, iglesia parroquial de Collesano (Sicilia). Fotografía reproducida en KRUFT, HannoWalter: Antonello Gagini und seine söhne. Munich, 1980.

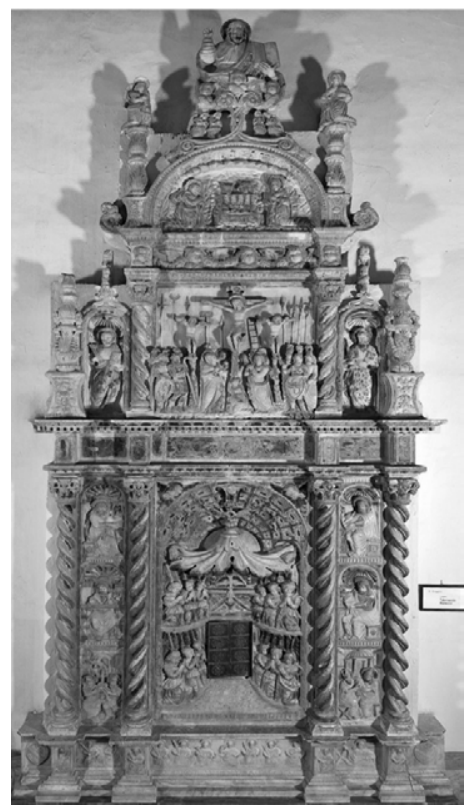




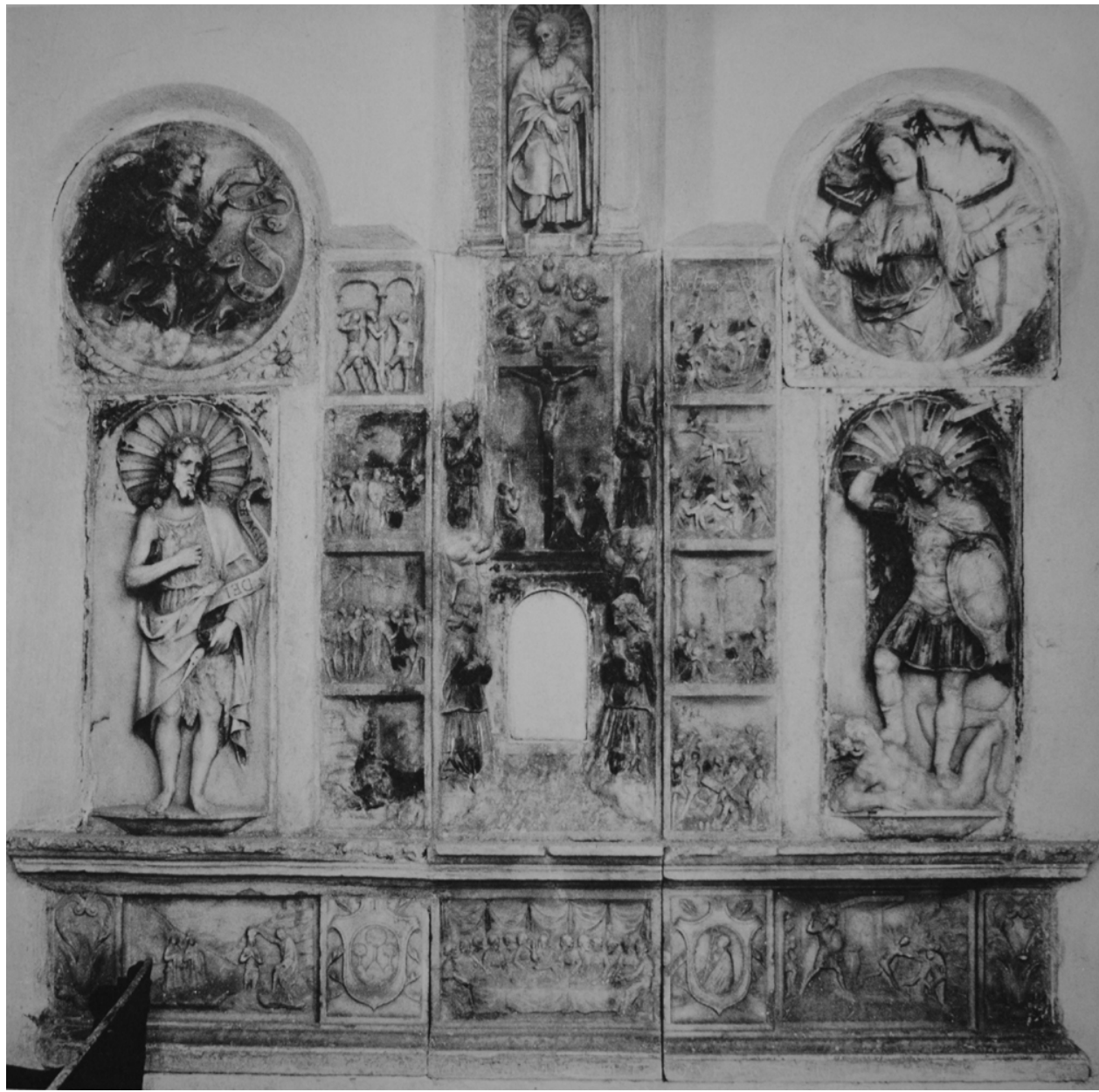

Figura 8. Atribuido a Antonello Gagini, Sagrario, principios del siglo XVI, Badia Grande de Alcamo (Sicilia). Fotografía reproducida en FAILLA, Marco: "La commitenza del vescovo Francesco Vitale (1484-1492) tra Collesano, Isnello e Cefalù e la diffusione dei tabernacoli marmorei di tipología rinascimentale nel territorio delle Madonie", en Arte e storia delle Madonie. Studi per Nico Marino. T. III. Cefalù, 2016. 